\title{
Corrosion Minimization For Research Reactor Fuel
}

\author{
Eric Shaber \\ Gerard Hofman, ANL
}

June 2005

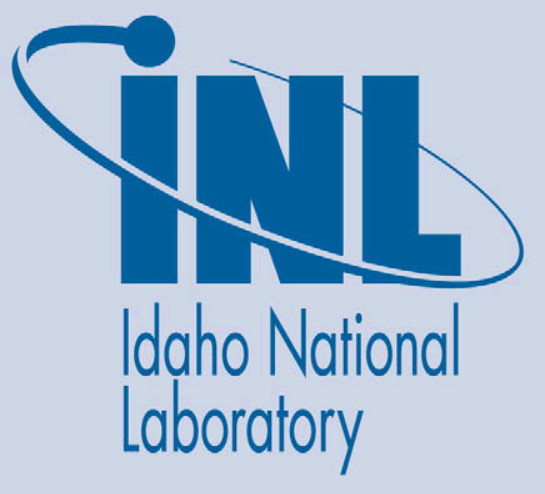

The INL is a U.S. Department of Energy National Laboratory operated by Battelle Energy Alliance 


\title{
Corrosion Minimization For Research Reactor Fuel
}

\author{
Eric Shaber \\ Gerard Hofman, ANL
}

June 2005

\section{Idaho National Laboratory \\ Reduced Enrichment Research Test Reactor Program \\ Idaho Falls, Idaho 83415}

Prepared for the

U.S. Department of Energy

National Nuclear Security Administration

Under DOE Idaho Operations Office

Contract DE-AC07-05ID14517 
This page left intentionally blank. 


\section{Contents}

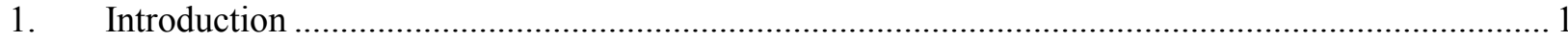

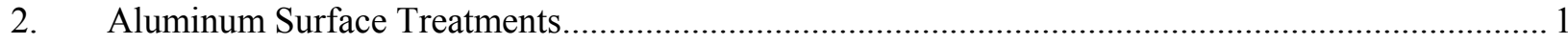

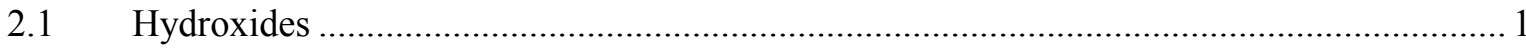

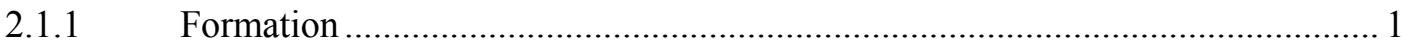

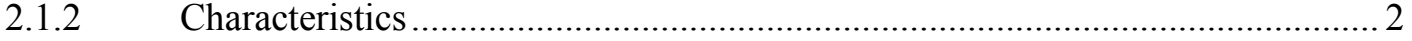

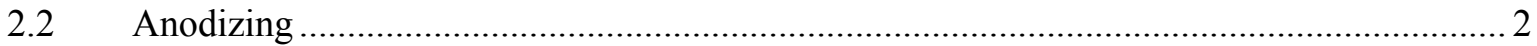

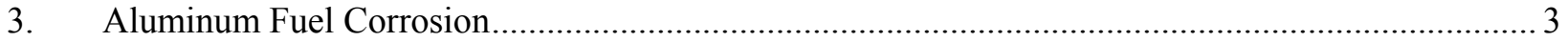

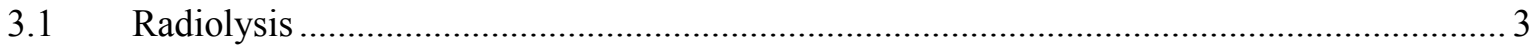

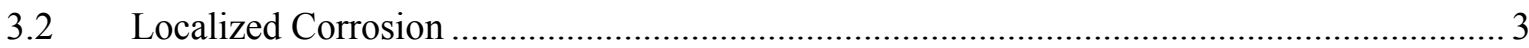

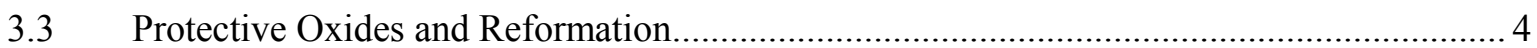

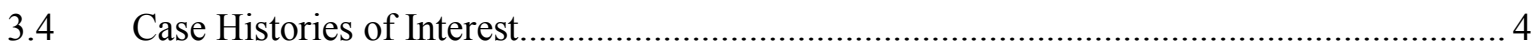

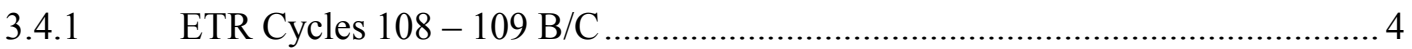

Iowa State UTR - 10 Fuel Plate Corrosion..................................................... 5

3.4.3 RERTR Program Cladding Corrosion by Coolant ........................................... 7

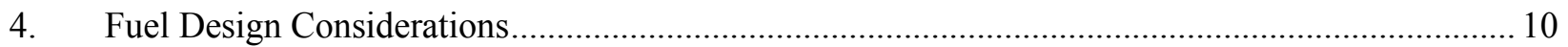

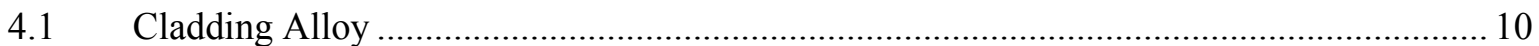

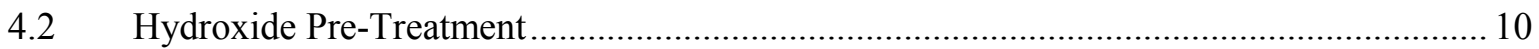

5. Fuel \& Reactor Operation "Best Practices"................................................................................ 11

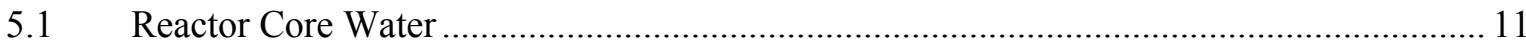

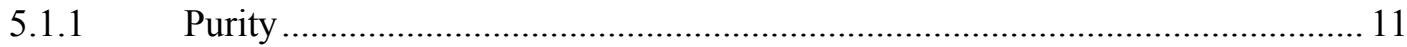

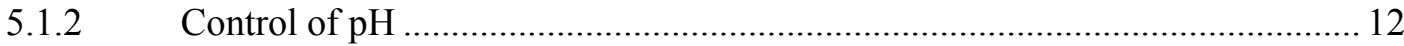

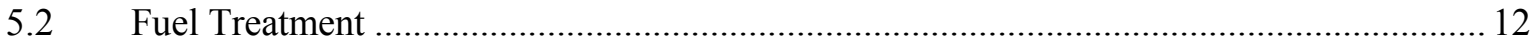

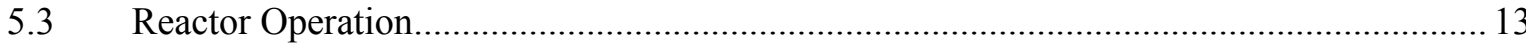

5.3.1 Impacts of Reactor Operating Temperature ….............................................. 13

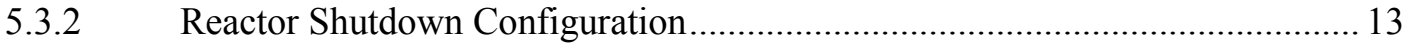

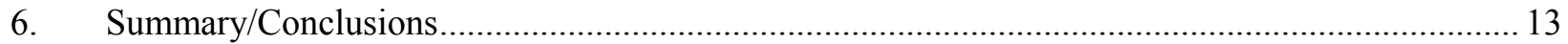

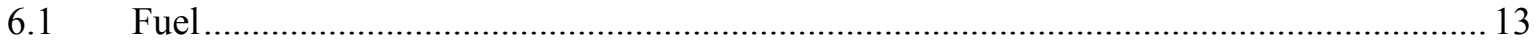




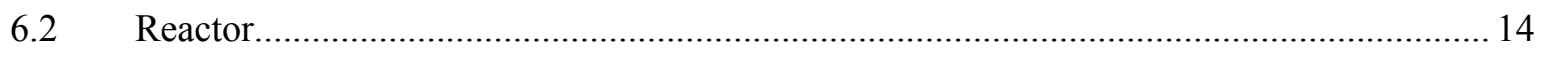

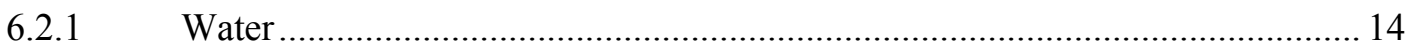

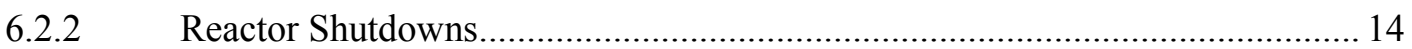

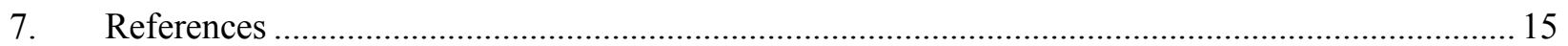




\section{Corrosion Minimization For Research Reactor Fuel}

\section{Introduction}

Existing university research reactors are being converted to use low-enriched uranium fue to eliminate the use of highly-enriched uranium. These conversions require increases in fuel loading that will result in the use of elements with more fuel plates, resulting in a net decrease in the water annulus between fuel plates.

The proposed decrease in the water annulus raises questions about the requirements and stability of the surface hydroxide on the aluminum fuel cladding and the potential for runaway corrosion resulting in fuel over-temperature incidents. The Nuclear Regulatory Commission (NRC), as regulator for these university reactors, must ensure that proposed fuel modifications will not result in any increased risk or hazard to the reactor operators or the public.

This document reviews the characteristics and behavior of aluminum hydroxides, analyzes the drivers for fuel plate corrosion, reviews relevant historical incidents, and provides recommendations on fuel design, surface treatment, and reactor operational practices to avoid corrosion issues.

\section{Aluminum Surface Treatments}

\subsection{Hydroxides}

\subsubsection{Formation}

At temperatures below $400^{\circ} \mathrm{C}$ in air or water, aluminum will form one of several hydroxides on exposed surfaces. When the temperature of formation is below $\sim 77^{\circ} \mathrm{C}$, the end product will be a tri-hydroxide with the structure of Gibbsite (hydrargillite) $\left[\gamma-\mathrm{Al}(\mathrm{OH})_{3}\right]$, if the $\mathrm{pH}$ is lower than $\sim 5.8$ or higher than $\sim 9$; Bayerite $\left[\alpha-\mathrm{Al}(\mathrm{OH})_{3}\right]$, if the $\mathrm{pH}$ is between $\sim 5.8$ and $\sim 9$; or Nordstandite $\left[\mathrm{Al}(\mathrm{OH})_{3}\right]$, often considered a mixture of the other forms. When the temperature is above $\sim 77^{\circ} \mathrm{C}$ and below $\sim 102^{\circ} \mathrm{C}$, a pseudoboehmite structure is formed, which may age to other hydroxide forms or retain its pseudoboehmite structure. Between $\sim 102^{\circ} \mathrm{C}$ and $\sim 400^{\circ} \mathrm{C}$ and at pressures below $\sim 20 \mathrm{MPa}(2900 \mathrm{psi})$, crystalline boehmite $[\gamma-$ $\mathrm{AlOOH}]$ will form ${ }^{\mathrm{i}}$.

The technical understanding of how aluminum hydroxides form has improved greatly over the last 50 years. In water, these hydroxides are now known to form from precipitation and aging of gelatinous compounds of low crystal order and up to five moles of water per mole of oxide. Formation in water and from dilute acidic solutions is particularly important for understanding and predicting reactor fuel behavior.

The primary ionic species formed is $\left[\mathrm{Al}\left(\mathrm{H}_{2} \mathrm{O}\right)_{6}\right]^{3+}$, which provides the building block for octahedral chain molecules or hexagonal ring polynuclear complexes. Deprotonation and condensation reactions form a gelatinous boehmite that is the chemical precursor to both the tri-hydroxide and mono-hydroxide crystalline structures [Wefers 1987] (see Figure 1). Octahedral chain molecules, polynuclear complexes and the gelatinous boehmite structures need to be avoided within operating reactor nuclear fuel because their low-density structures are capable of blocking the annulus between fuel plates. Avoiding these 
chemical complexes in reactor service is achieved by preparing the fuel with the most appropriate hydroxide surface prior to usage and preventing the dissolution of that hydroxide during operation.
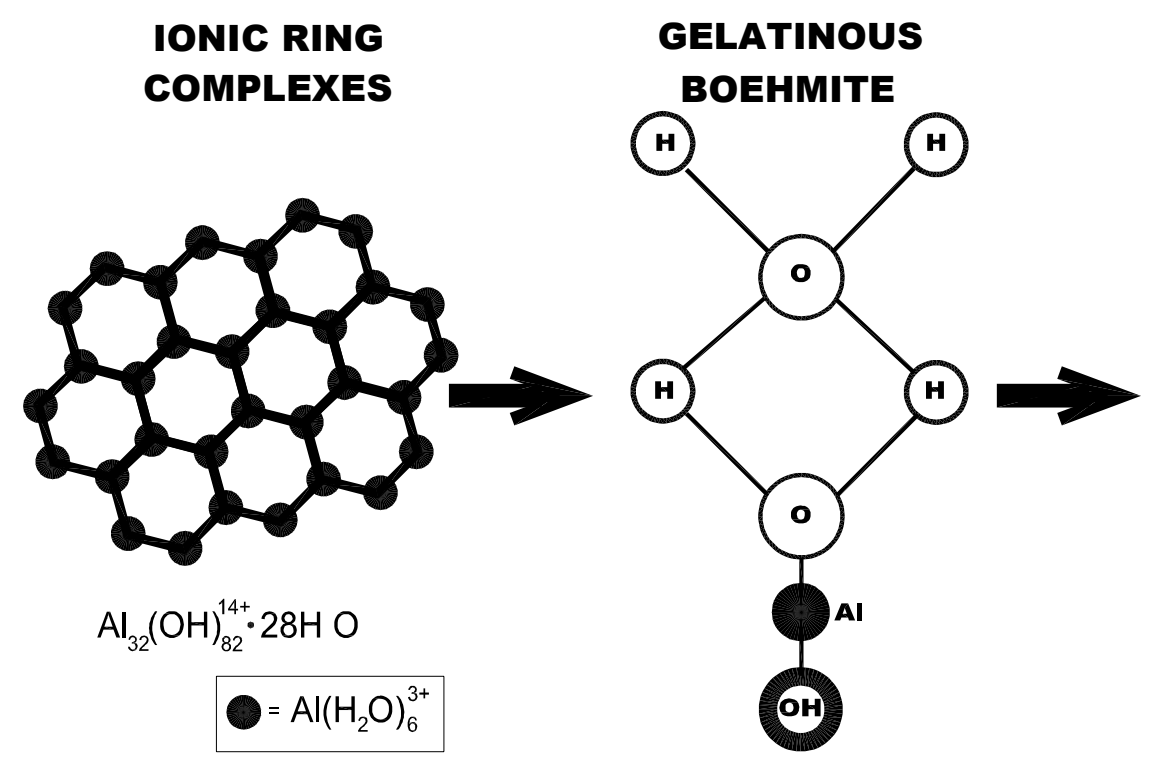

\section{CRYSTALLINE BOEHMITE}

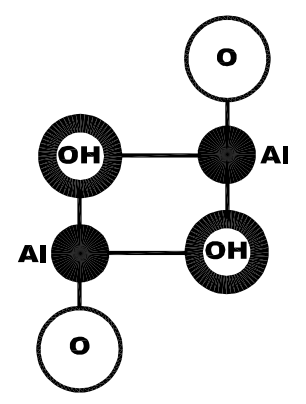

Figure 1. Precipitation and aging of Al hydroxide to boehmite

\subsubsection{Characteristics}

2.1.2.1 Region of Stability. Aluminum hydroxides are amphoteric but relatively stable over a specific range of $\mathrm{pH}$, primarily because of passivation due to the positive charge on the hydroxide surface provided by the $\mathrm{Al}^{3+}$ ion. The tri-hydroxide forms have a wider range of chemical stability ( $\mathrm{pH}$ of $\sim 4.0-$ 8.5) but do not provide exceptional corrosion resistance within the region of passivation. Crystalline boehmite (mono-hydroxide) has a narrower passivation range ( $\mathrm{pH}$ of $\sim 4.7-6.2$ ) but better water corrosion resistance within its range of stability. Boehmite treatments are commonly applied to improve the corrosion resistance of anodized aluminum components by "sealing" them in boiling water.

Crystalline boehmite is routinely applied to Advanced Test Reactor fuel assemblies prior to their usage by treating them with deionized water in a high-temperature autoclave.

2.1.2.2 Effect of Anions. Acidic anions, especially carbonate and sulfate have been shown to adversely affect the aging of aluminu gels to achieve stable crystalline compounds. Chloride and nitrate are also undesirable but somewhat less damaging. Carbonate appears to have the strongest retarding effect. Conversely, removal of acidic anions from the chemical system helps accelerate the aging process. Because of these interactions, it is important that water supplies and water treatment systems prevent contamination with $\mathrm{CO}_{2}$, carbonic acid, oxalic acid, or sulfuric acid.

\section{$2.2 \quad$ Anodizing}

Anodizing is an electrolytic method of depositing nearly pure $\mathrm{Al}_{2} \mathrm{O}_{3}$ on an aluminum surface. The metal is used as the anode in an electrolytic cell in an acidic electrolyte with a current applied to drive the chemical reaction with oxygen. Two basic types of anodizing treatments are in common use: those 
designed to provide a non-porous barrier oxide film, and those that generate a thick but porous structurally favorable coating. Porous anodic oxides are not discussed further as they could not perform the desired function. Barrier layer anodizing, however, could be used as an aluminum surface treatment. It could provide significant advantages over hydroxide coatings in that a very stable, fully crystalline alumina is generated.

Barrier layer anodizing involves an electrolyte of either ammonium tartrate or boric acid ${ }^{\mathrm{ii}}$ and an operating voltage of typically $200-300 \mathrm{~V}$ to generate an $\mathrm{Al}_{2} \mathrm{O}_{3}$ layer of up to $0.2 \mu \mathrm{m}$ thickness. The layer formed is relatively pure $\mathrm{Al}_{2} \mathrm{O}_{3}$ but it will contain up to one percent of the acidic ion used in its formation. Boric acid electrolytes would be unacceptable for nuclear fuel. Although technically attractive, this approach to pretreatment does not have an existing experience base for use with nuclear fuel and would require testing for qualification before it could be seriously considered as a pre-treatment approach.

\section{Aluminum Fuel Corrosion}

Corrosion is essentially an electrochemical process that may be enhanced by mechanical interactions or stresses on the components involved. Since aluminum is protected by a "corrosion" product, the term corrosion used here is defined as uncontrolled or unexpected hydroxide growth or change. Corrosion rates may be altered significantly (either positively or negatively) as a result of combinations of dissimilar metals or the application of electric currents. Conversely, corrosion can generally be minimized by maintaining water purity and preventing interactions with dissimilar materials in the reactor. The corrosion issues experienced with aluminum research reactor fuels are radiolysis and localized corrosion.

\subsection{Radiolysis}

Neutron radiolysis is currently thought to cause breakdown of water molecules in the reactor coolant by ionization of the water to yield $\mathrm{H}_{2} \mathrm{O}^{+}$, radical-cations, fast electrons, and electronically excited water molecules. The fast electrons rapidly thermalize and are solvated by interaction with neighboring water molecules to form what is chemically an anion of the hydrogen radical. This anion is the strongest known reducing species with a reduction potential of $-2.9 \mathrm{~V}$ at a $\mathrm{pH}$ of 7 . As a result, the anion rapidly grabs oxygen (from the water or from the aluminum hydroxide surface) to form $\mathrm{O}_{2}{ }^{-}$that is a strong oxidizing agent and the precursor for formation of $\mathrm{H}_{2} \mathrm{O}_{2}$. The $\mathrm{H}_{2} \mathrm{O}^{+}$ions also decompose rapidly to form the $\mathrm{OH}^{-}$ radical that may recombine as $\mathrm{H}_{2} \mathrm{O}, \mathrm{H}_{2} \mathrm{O}_{2}$, or $\mathrm{HO}_{2}$. Radiolysis reactions are typically at a maximum near the surface of active fuel plates. The first few atom layers of water molecules next to the surface are affected both because of their proximity to the fission reaction and because of the nearly nonexistent flow rate of the water at the surface of the fuel. Radiolysis reactions cannot be avoided on nuclear fuel cladding surfaces. The radiolysis reaction, however, may either accelerate corrosion by facilitating the cathodic process or reduce the corrosion by anodic passivation ${ }^{\text {iii }}$.

\subsection{Localized Corrosion}

Localized corrosion may occur in locations where water stagnates or is allowed to concentrate through evaporation such that its oxygen potential decreases and its ionic activity and acidity can increase beyond the hydroxide passivation range allowing the aluminum and/or its hydroxides to be attacked or dissolved. Localized corrosion includes pitting, galvanic, filiform, and crevice corrosive attack and often more than one specific mechanism is involved with corrosion issues. Although bulk reactor core water is normally quite clean, water that stagnates in corners, crevices, connector boxes, (or water that pools in such locations when the core is drained) may tend to increase in conductivity to the point that it becomes an effective electrolyte, allowing the corrosion mechanism to kick in. 
Localized corrosion is always exacerbated by galvanic interaction where dissimilar metals are in electrical contact and the electrical potential difference between the materials helps strip the positive charge from the anode and drive the corrosion reaction. Probably the most common situation with aluminum-clad fuels is contact with stainless steel components or reactor hardware. The difference in electro-negativity between the two metals promotes current flow leading to Al corrosion. The galvanic coupling of aluminum and stainless steel has been an especially difficult issue for spent fuel in water basins.

\subsection{Protective Oxides and Reformation}

Most fuel cladding materials are active metals ( $\mathrm{Al}, \mathrm{Zr}, \mathrm{Mg}, \mathrm{Cr}$, or $\mathrm{Ni}$ ) where the cladding metal is protected from water corrosion by a stable passive surface compound containing oxygen. Radiolytic decomposition of surface oxides or hydroxides tend to be countered by reformation reactions that rebuild the surface protective layer. Therefore, the measurable effects of radiolysis may be very small if the cladding material rebuilds a structurally equivalent passive surface layer in rapid response to the radiolytic reactions taking place. This happens with $\mathrm{Zr}$ alloy commercial nuclear fuel cladding where core conditions are quite similar to the autoclave pre-filming conditions initially used to form the protective oxide. The $\mathrm{Zr}$ will continually re-form surface oxides damaged or lost during reactor operation.

Although similar in principle, the re-formation of Al hydroxides is subject to the thermal limitations involved with specific $\mathrm{Al}$ hydroxides as matched with the reactor operating parameters. For example, the ATR reactor uses Al fuel protected with an autoclaved crystalline boehmite surface. Although the core water average temperature is only about $68^{\circ} \mathrm{C}$ the surface temperature of the fuel is considerably higher and is sufficient to form at least a pseudoboehmite structure when/if the hydroxide is damaged by radiolysis.

For research reactor operations, where the average core water outlet temperature is around $38^{\circ} \mathrm{C}$, the hydroxide resulting from reformation reactions would be difficult to predict without detailed data on the surface temperature and heat flux history for the fuel involved ${ }^{\text {iv }}$.

\subsection{Case Histories of Interest}

\subsubsection{ETR Cycles $108-109$ B/C}

3.4.1.1 Incident. An incident occurred with the Engineering Test Reactor at Idaho with operating cycle 108. Maintenance work had been performed prior to startup and on startup the water was turbid. Some ion exchange resin had gotten into the primary water boosting the $\mathrm{Cl}$ content. The $\mathrm{pH}$ of the primary water was reduced using $\mathrm{CO}_{2}$ with the intent of obtaining a $\mathrm{pH}$ of 5.0 but extra $\mathrm{CO}_{2}$ was added as the initial additions did not appear to have the desired effect on the bulk water $\mathrm{pH}$. After beginning operations in this mode, a fuel failure indication resulted in reactor shutdown. Investigation showed that a fuel plate had buckled from overheating resulting in cladding failure.

3.4.1.2 Analysis. Significant effort was expended trying to determine the exact cause of this incident ${ }^{\mathrm{v}}$. Unfortunately, the incident occurred before the chemistry of aluminum hydroxide was thoroughly understood. Although the details cannot be stated at this point with certainty, the following summary technical sequence is thought to be a good explanation of what happened:

1. Turbidity in the water was aluminum hydroxide particulate and colloids mixed up from the maintenance activities. 
2. Attempts to reduce the $\mathrm{pH}$ using $\mathrm{CO}_{2}$ did not work as expected because the carbonate ion was attaching itself to the aluminum hydroxides in the water and on the surfaces of the fuel.

3. As the $\mathrm{pH}$ at the aluminum surfaces went lower, large quantities of the hydroxide went into solution.

4. When reactor operation started, the coolant began heating and the $\mathrm{Al}$ in solution began the deprotonization/condensation sequence to re-precipitate as the ionic compound $\left[\mathrm{Al}\left(\mathrm{H}_{2} \mathrm{O}\right)_{6}\right]^{3+}$ at the hottest location in the core: the fuel surface. The carbonate present, however, prevented normal aging of the hydroxide.

5. The formation of polynuclear rings/gel chain molecules and gelatinous boehmite at the fuel surface caused a rapid increase in "hydroxide" thickness that blocked water flow and prevented heat transfer.

6. The fuel overheated and buckled causing cladding failure.

During the next cycle at ETR, $(109 \mathrm{~A})$ the $\mathrm{pH}$ was tightly controlled at exactly 5.0 but carbonate ion was still present. The historical account of this cycle states:

Beginning with cycle 109, the corrosion product film was a "soft", "tacky", "spongy", material in varying degrees and appeared to be soluble, with some position dependence.

This historical account is a very good description of gelatinous boehmite that was not able to age to its crystalline form as a result of the carbonate present in the system.

For the next cycle at ETR, $(109 \mathrm{~B} / \mathrm{C})$ the $\mathrm{pH}$ was increased back to $\sim 5.5$ and the filterable solids containing much of the carbonate had been effectively removed from the water by filtration. As a result, the fuel surface hydroxides aged back to their original condition and the entire system returned to normal. lowa State UTR - 10 Fuel Plate

\section{Corrosion}

3.4.2.1 Incident. A relevant and more recent event of unexpected fuel plate corrosion occurred with UTR - 10 fuel plates at the Iowa State University reactor in the early 1990's. These fuel plates were low enriched uranium fuels designed to replace highly enriched plates used previously. Because of the low enrichment, additional fuel plates were required in each element which resulted in a reduction of the water annulus between fuel plates. The fuel plate surfaces were not pre-treated before being placed into service. The fuel plates were made using 6061aluminum in an "O" temper

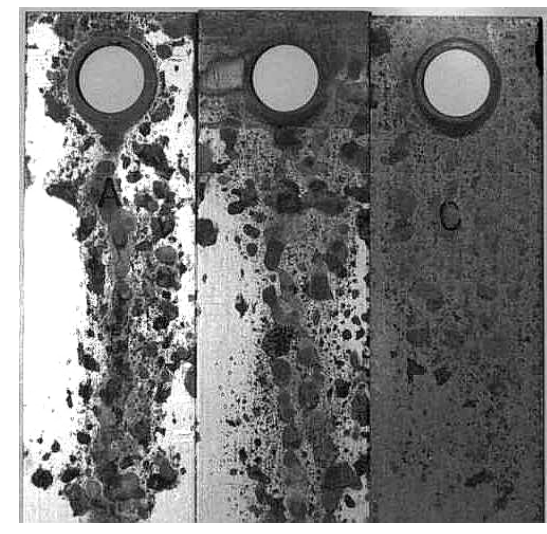

Figure 2: Three Dummy fuel plates after exposure condition. Shortly after initial loading in August 1991, unexpected "staining" and corrosion was noted on the fuel plates. The corrosion was more severe and dissimilar to that noted on the fuels used previously. In an attempt to correct the issue, the core water was changed out in November 1991.

In an attempt to determine the cause of the corrosion, dummy plates of exactly the same material and fabrication history were placed in the core in March 1992. The plates were removed and inspected after each 20 hours in reactor core water. For inspection, the plates were removed from their holder, cleaned 
with ALCONOX, rinsed, dried, and photographed. Corrosion was noted almost immediately and the corrosion continued to develop with time. Corrosion was found to be most severe around the stainless steel pins used to hold the samples in the core (See Figure 2). However, other spotty corroded areas were noted and locations were found where the corroded material [analyzed as $\alpha-\mathrm{Al}(\mathrm{OH})_{3}$ ] had apparently separated from the base metal. In all, the dummy samples were in the core for about 6.5 years, exposed to reactor water for 234 hours, and experienced 318 wet - dry cycles.

An initial analysis of the dummy fuel plate corrosion was performed by Hofman in $1993^{\mathrm{vi}}$ that indicated that nothing was in the water that would account for the corrosion. It concluded that:

- That the overall corrosion was bayerite formation from prolonged exposure of wet fuel plates in ambient air.

- That pitting corrosion was taking place underneath the bayerite crust, likely due to pollutants entering the core from the air when the core water was drained. ( $\mathrm{Ca}$ and $\mathrm{Cl}$ were suspected, and precipitates of a calcium compound (possibly $\mathrm{CaCO}_{3}$ ) were found on the pitted surface.) (The authors guessed that the source of the calcium was concrete sawing dust from building construction in progress adjacent to the reactor building.)

Additional analysis of the Iowa State dummy test coupons was performed by Shaber in 1999 to determine the usability/disposition of the fuels from the reactor ${ }^{\text {vii }}$. This analysis concluded that the fuel was usable and that the pitting reached a maximum depth of only $18 \mu \mathrm{m}(0.0007 \mathrm{in})$ which was less cladding loss than would result from acid or caustic cleaning and re-treatment of the fuel surfaces.

3.4.2.2 Analysis. Although insufficient information is available on this corrosion situation to fully define exactly why the fuel staining corrosion occurred, a lot is known about the incident and the dummy test materials. The analysis [Hofman 1993] stated that the water chemical analysis found no obvious impurities or deviation from acceptable values for $\mathrm{pH}$ and electrical conductivity, but this was not the core water involved when the fuel corrosion occurred initially. A tangible hypothesis is that the original staining corrosion was a direct result of poor core water quality during the first few days in operation when the fuel bayerite layer was actively growing in thickness from a few nanometers to approximately $0.5 \mu \mathrm{m}$. Without detailed information on the water quality of the core water in use at the time, detailed understanding of the corrosion product will not occur short of performing post irradiation examination of the fuel plates.

The dummy fuel corrosion test had design problems. The corrosion around the pins holding the dummy plates in place was obviously accelerated by galvanic interaction. It is postulated that normal cracks and fissures in the surface hydroxide, with assistance from the galvanic couple and chloride ion allowed localized crevice corrosion to occur resulting in the dark blisters noted in Figure 2. Crevice corrosive attack would promote the localized spalling of the hydroxide noted by Hofman. The cleaning of the samples every 20 hours used ALCONOX cleaner with a $\mathrm{pH}$ of 9.5 that contained 7 $13 \%$ sodium carbonate. The cleaning solution would have been effective in removing part of the hydroxide each time it was used and would have left residual

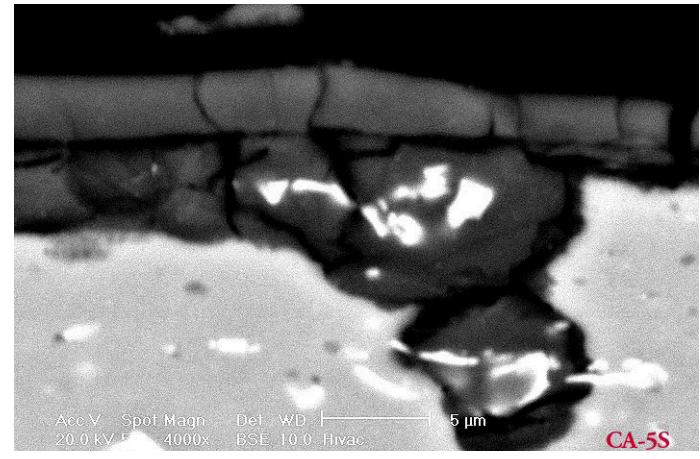

Figure 3: Hydroxide pit surrounding $\mathrm{Mg}-\mathrm{Si}-\mathrm{Fe}$ particles 
carbonate that would prevent full aging and passivation of the surface; therefore, the corrosion would continue with a new dose of carbonate every 20 hours.

The presence of $\mathrm{CaCO}_{3}$ was suspected on the dummy fuel. If it was not present in the core water, it could have come from pre-existing water spots on the dummy samples, from sample cleaning solutions, or external sources as presumed by Hofman. Only carbonate from the core water, however, would have actually affected the fuel and not just the dummy plates.

The pitting noted in the Hofman analysis is not expected to be from external contaminants, but alloying elements in the dummy fuel cladding. This type of micropitting is normal in 6061-O Al that has been treated to form a surface hydroxide ${ }^{\text {viii }}$. The pitting occurs at every location where the hydroxide surrounds a second phase particle in the aluminum that was in contact with the surface during hydroxide formation. These second phase particles (typically $\mathrm{Mg}-\mathrm{Si}-\mathrm{Fe}$ ) are large particles because of the fully annealed condition of the $6061 \mathrm{Al}$ involved. Because the hydroxide grows and surrounds the surface connected particles, they would tend to be removed with the hydroxide when it spalls leaving the pitted surface noted in Hofman's analysis. In the second analysis [Shaber 1999] the pitting was confirmed to be due to hydroxide surrounding surface-connected second phase particles (see Figure 3).

\subsubsection{RERTR Program Cladding Corrosion by Coolant}

As described in detail in the preceding sections, a general feature in water-cooled reactors is the formation of corrosion products on the fuel cladding surface. The primary detrimental property of aluminum hydroxide is its low thermal conductivity, approximately one tenth that of the A1 cladding. It is a thermal barrier to the heat flow from the cladding to the water and causes the cladding and fuel meat temperature to increase. Corrosion does not present operational problems for typical low and medium power research reactors using fuels without pretreatment. As shown in Fig. 4 for fuel plates irradiated in the 30-MW Oak Ridge Research Reactor, the corrosion layers are uniform, adherent, and about $20 \mu \mathrm{m}$ thick, for two Al-Mg cladding alloys used by European manufactures and the standard A16061 alloy used in the US.

Table 1 shows a collection of corrosion layer thickness data obtained during the RERTR fuel test programs carried out in various research reactors. The appearance of the corrosion layers is very similar to those shown in Figure 4. No evidence of pitting has been observed, and where x-ray diffraction was performed the corrosion was found to consist of a mixture of Bayerite and Boehmite. There appears to be no discernable difference in the corrosion behavior of the solution hardening Al-Mg alloys (AlMg2, Ag2Ne, etc. which are comparable to the 5000 type alloys) and the dispersion hardening alloys (SAV 1 and 6061). All cladding alloys were, because of the hot

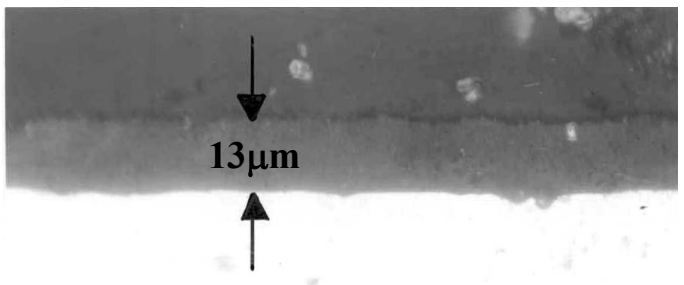

AG5NE

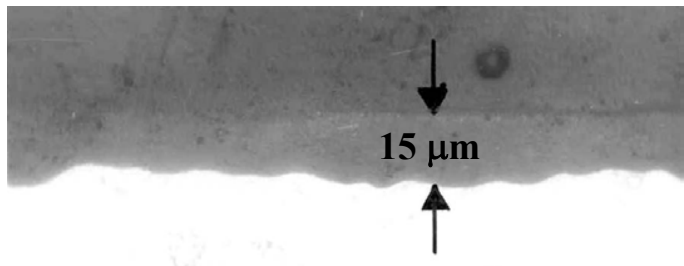

$\operatorname{AlMg}_{2}$

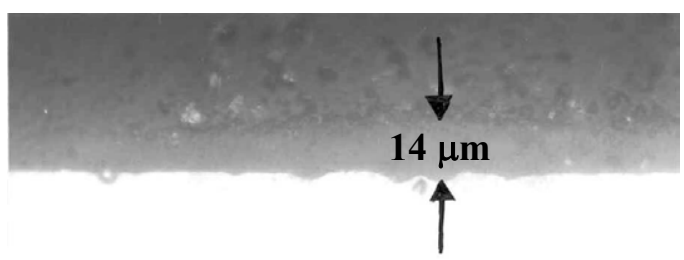

\section{AA6061}

Figure 4: Boehmite layers on various $\mathrm{Al}$ cladding alloys irradiated in ORR for $\sim 300 \mathrm{~d}$, pH $5.5-6.5$ 
rolling and blister anneal procedures, in a fully annealed condition with, depending on the finishing fabrication step, a small $(\sim 10 \%)$ amount of cold work. None of the reactors employ pH reduction by coolant acidification, nor do they pre-film the cladding.

We may conclude from this experience that in reactor corrosion is not a fuel performance issue in any of these varied reactors if, as is the case for all listed in Table 1, coolant water purity is maintained by deionization, within a narrow $\mathrm{pH}$ range and at low conductivity values.

At he $\varepsilon^{2}$ fluxes typical of the reactors in Table 1, the cladding temperature is only modestly increased by the presence of the corrosion product. However, for higher power density reactors such as the ATR, corrosion was recognized early as a potential performance issue. The ATR (and SRS production reactors) have been operated quite successfully by pre-treating the fuel cladding with a very thin, highly crystalline layer of boehmite. This layer minimizes the temperature differential across the hydroxide layer, eliminates spalling, and helps preclude significant additional hydroxide growth during irradiation.

Table 1: Corrosion layer thicknesses on irradiated Al-Clad dispersion fuels used without pre-filming with aluminum hydroxide

\begin{tabular}{|c|c|c|c|c|c|}
\hline Reactor & Alloy & $\begin{array}{l}\text { Thickness } \\
\quad(\mu \mathrm{m})\end{array}$ & $\begin{array}{c}\text { Water } \\
\text { pH }\end{array}$ & 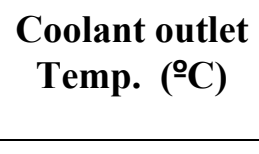 & $\begin{array}{c}\text { Surface Heat } \\
\text { flux } \\
\left(\mathrm{W} \mathrm{cm}^{-2}\right) \\
\end{array}$ \\
\hline ORR & $\begin{array}{l}\text { AlMg2 } \\
\text { AG3NE } \\
6061\end{array}$ & $\begin{array}{l}24 \\
20 \\
24\end{array}$ & $5-6.3$ & 53 & 120 \\
\hline HFR & AG5NE & 45 & 6.70 & 55 & 120 \\
\hline RGAS & AIMg2 & 40 & $6.5-7.0$ & 54 & 60 \\
\hline NRU & 6102 & 35 & $5.5-6.5$ & 70 & 250 \\
\hline JMTR & $\mathrm{AlMg} 2$ & 20 & $5.5-6.0$ & 45 & 100 \\
\hline IVV-2M & $\begin{array}{l}\text { AlMg2 } \\
\text { SAV-1 }\end{array}$ & 25 & 6 & 40 & 70 \\
\hline RA3 & 6061 & 12 & $5.0-6.2$ & 35 & 40 \\
\hline OSIRIS & AG2NE & 35 & 6 & 47 & 130 \\
\hline
\end{tabular}


An example of the efficacy of pre-filming is shown in Figure 5 for the RERTR tests performed in ATR. Test plates in RERTR-1 and 2 were not pre-filmed and experienced severe corrosion-erosion and occasional pitting whereas the pre-filmed RERTR-3, 4 and 5 test plates ${ }^{\mathrm{a}}$ showed uniform adherent and thin boehmite layers over the clearly visible fuel regions.
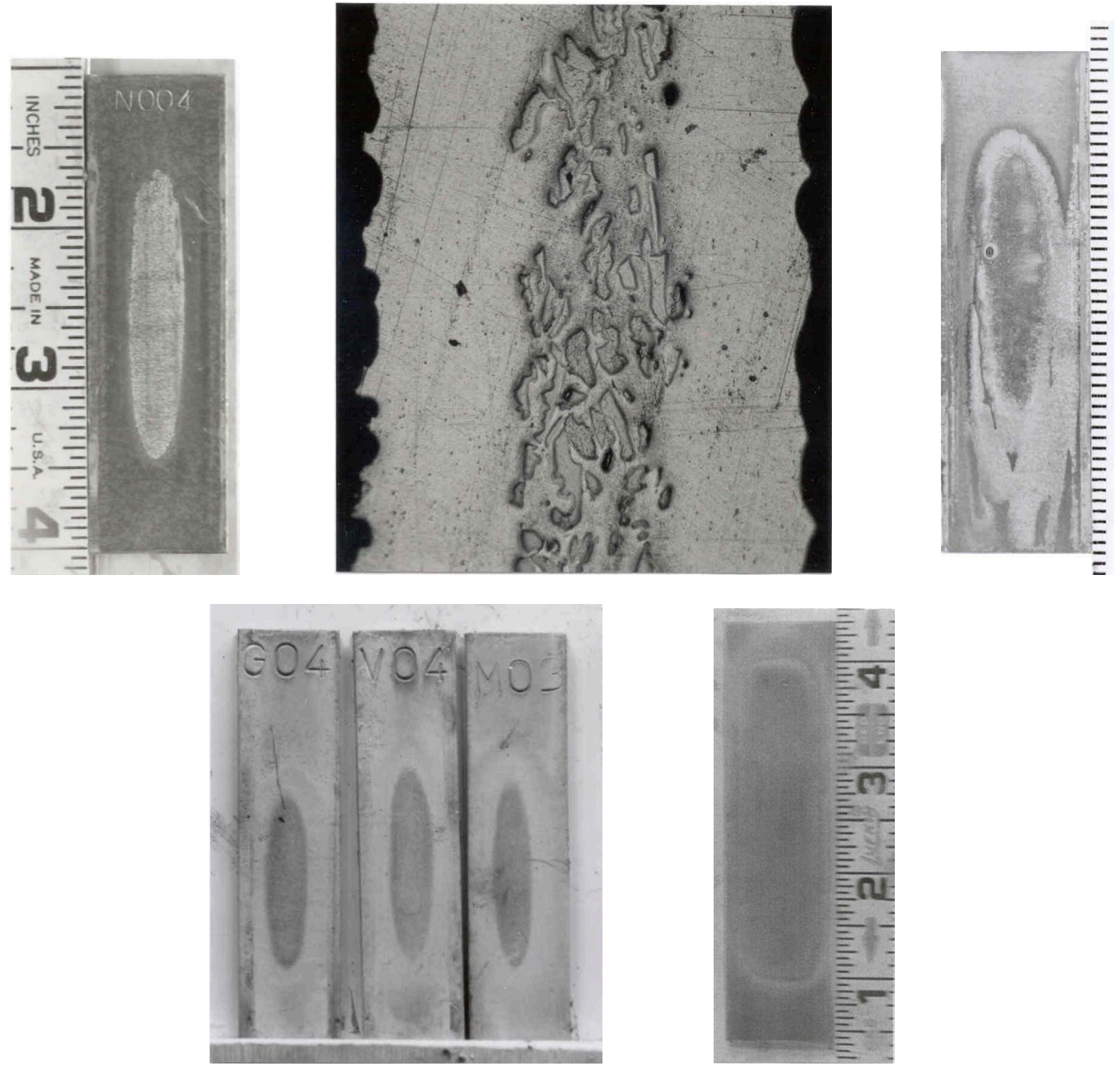

Figure 5: Aluminum cladding corrosion, upper: untreated RERTR-2; lower: Prefilmed RERTR-3 and 4.

\footnotetext{
${ }^{\text {a }}$ Prefilming performed at $180^{\circ} \mathrm{C}$ for 48 hours at $\mathrm{pH}$ of 5.0.
} 


\section{Fuel Design Considerations}

\subsection{Cladding Alloy}

Aluminum is the cladding material of choice for research reactor plate fuels because of its neutron transparency, high thermal conductivity, oxide/hydroxide stability in water, availability, and cost. Although there is no doubt that aluminum should be the cladding material, the specific alloy and the finished condition should be considered carefully. Early fuel development efforts utilized the 1100 alloy (99\% pure aluminum) with great success. This evolved to use of "AlCLAD" in which the 1100 alloy was roll-bonded to 6061 alloy to improve strength and welding compatibility with end boxes/hardware and match thermal expansion coefficients, and then to exclusive use of 6061 alloy in the fuel cladding. These two alloys became the standards in the nuclear industry for fuel cladding as their operating database grew.

Other than historical precedent, however, the use of 6061 for fuel cladding may not be the best choice. In practice it is impractical to take the 6061 fuel cladding back to its T6 (heat treated and precipitation aged) condition as part of the fuel fabrication process. The annealed alloying compounds provide no beneficial effect in the alloy and those in contact with the cladding surface cause the micro-pitting [Shaber 1998] discussed previously.

If historical precedent were ignored, the optimum technical solution to prevent micro-pitting would be to change alloys. If cladding mechanical strength is not a significant issue and welding is not required, pure aluminum (AA1070 alloy ${ }^{b}$ ) should be considered for fuel cladding. If additional strength is required without weldability, 5000 series alloys should be considered to match or increase the strength of the AA6061 in the "O" temper, eliminate the undesirable addition of $\mathrm{Cu}$, and remove the Si that is not serving its intended purpose.

However, it must be emphasized that AA6061 has been used quite successfully as a fuel cladding material for many years reactor service, even in the most demanding of reactor conditions. Although micropitting is undesirable, it has not been a fuel performance issue. Therefore, AA6061 must be considered a fully acceptable cladding material.

\subsection{Hydroxide Pre-Treatment}

As a design consideration, the hydroxides of aluminum have a much lower thermal conductivity than the base metal. Therefore, the hydroxide surface layer on aluminum fuel plates must be limited in thickness to prevent fuel overheating. It is also essential that the hydroxide thickness be relatively consistent to prevent the formation of localized hot spots or areas that abnormally stress the fuel plate and can warp a fuel element to the extent that the water annulus is reduced or eliminated.

Historical practice with Advanced Test Reactor fuel that is supported by thermal modeling data and many years of successful operating history places the maximum allowable hydroxide thickness on the surface of fuel cladding at 0.00135 " or $34 \mu \mathrm{m}$ for ATR reactor conditions ${ }^{\text {ix }}$. The ATR fuel hydroxide application process, is specified ${ }^{\mathrm{x}}$ to require application of hydroxide within the thickness range of $1.5-7.6 \mu \mathrm{m}$ $(0.00006-0.0003 \mathrm{in})$, and the actual average thickness resulting from the current process is $1.92 \mu \mathrm{m}$

\footnotetext{
${ }^{\mathrm{b}}$ Alloy 1070 is designated rather than 1100 because the 1100 alloy has evolved over the last 40 years to become more of a general purpose "trash" alloy. Alloy 1070 is $99.7 \%$ pure aluminum and will provide better, more consistent performance than 1100 .
} 
(0.000076") [Shaber 1998]. This layer thickness is still much more than is actually needed to protect the aluminum surface from water corrosion ${ }^{\mathrm{xi}, \mathrm{c}}$.

Research reactor fuels have historically not been treated or coated prior to usage. Normal air exposure of the fuel prior to usage, starting from a chemically cleaned surface would be expected to result in a trihydroxide of only $2-10 \mathrm{~nm}$ in thickness. When inserted in the reactor core water and heated, the hydroxide will grow. In pure water, the hydroxide growth should reach a limiting thickness (typically $<$ $0.5 \mu \mathrm{m}$ ) within a few days. At the limiting thickness, the hydroxide should remain stable. Neutron radiation will adversely affect the growth of the hydroxide layer. Tests have shown that hydroxides grown under irradiation grow much thicker and are less resistant to chemical attack than hydroxides grown outside the radiation field ${ }^{\mathrm{xi}}$. Abnormal water $\mathrm{pH}$, high conductivity, or retarding anions may also radically change the limiting thickness or prevent the hydroxide from ever reaching a limiting thickness. Historical situations like the Iowa State fuel corrosion incident show that normal development of the surface layer does not always occur as expected. The surface hydroxide may vary widely in thickness and stability if it was formed while the reactor was in operation or at locations where the surface came into contact with unwanted chemical species (packaging materials, fingerprints, oils, sulfur rich exhaust fumes, high levels of $\mathrm{CO}_{2}$, or other anion sources) that adversely affect the normal aging and passivation of the hydroxide.

A process for application of an effective hydroxide pretreatment $(0.2-0.5 \mu \mathrm{m}$ thick boehmite $)$ for research reactor fuel would have the following parameters:

- $\quad$ Temperature $-185 \pm 8^{\circ} \mathrm{C}$

- $\mathrm{pH}-5.6-6.0$

- Time -8.0 hours

- $\quad$ Pressure $-130 \pm 30$ psig

- Preheat time - 4 hours

\section{Fuel \& Reactor Operation "Best Practices"}

\subsection{Reactor Core Water}

\subsubsection{Purity}

The ASTM provides a standard specification for reagent waters (ASTM D 1193 - 99) that provide a reasonable yardstick for evaluating water quality. The specification defines four types of waters as shown in Figure 6. Maintaining type 1 water quality in a reactor core would be highly desirable but is probably not feasible. Type IV water is not acceptable because of the potential dirt (Si and organic carbon) and the wide band of possible $\mathrm{pH}$. Type II and Type III water should be acceptable although tighter control over organic carbon than allowed in Type III water is preferred when aluminum fuel is involved. These water

\footnotetext{
${ }^{\mathrm{c}}$ Development testing to finalize the ATR boehmite application process showed that within the normal passivation band for boehmite $(\mathrm{pH} \sim 4.7-6.2)$, the maximum hydroxide thickness that could be achieved was $\sim 0.6 \mu \mathrm{m}$ in deionized water at $185^{\circ} \mathrm{C}$ at $0.9 \mathrm{MPa}$ for 18 hours. To achieve the specified hydroxide thickness the treatment water $\mathrm{pH}$ was raised above the normal passivation range to increase the hydroxide thickness.
} 
purity considerations are also consistent with IAEA guidance for corrosion protection of aluminum-clad fuel in water ${ }^{\text {xiii }}$.

\subsubsection{Control of $\mathrm{pH}$}

Some confusing technical data is present in the literature on the best $\mathrm{pH}$ of primary water in contact with aluminum nuclear fuel. The majority of the data available indicates that the minimum corrosion rates will occur by being centered within the passivation region for the hydroxide fuel surfaces involved. Another set of data, however, effectively ignores passivation and sets the optimum $\mathrm{pH}$ at the equilibrium between the $\mathrm{AlO}_{2}{ }^{-}$ion and the $\mathrm{Al}^{3+}$ ion in solution that occurs at a $\mathrm{pH}$ of $5.07^{\mathrm{d}}$. Other data indicates that this equilibrium $\mathrm{pH}$ tends to drop to below 5.0 with increases in temperature above $90^{\circ} \mathrm{C}^{\mathrm{xiv}}$.

\begin{tabular}{|c|c|c|c|c|}
\hline $\begin{array}{l}\text { Electrical conductivity, } \\
\max , \mu \mathrm{S} / \mathrm{cm} \text { at } 298 \mathrm{~K} \\
\left(25^{\circ} \mathrm{C}\right)\end{array}$ & $\begin{array}{l}\text { Type I } \\
0.056\end{array}$ & $\begin{array}{l}\text { Type } \| \\
1.0\end{array}$ & $\begin{array}{l}\text { Type III } \\
0.25\end{array}$ & $\begin{array}{l}\text { Type IV } \\
5.0\end{array}$ \\
\hline $\begin{array}{l}\text { Electrical resistivity, min, } \\
\mathrm{M} \Omega \cdot \mathrm{cm} \text { at } 298 \mathrm{~K}\left(25^{\circ} \mathrm{C}\right)\end{array}$ & 18 & 1.0 & 4.0 & 0.2 \\
\hline $\mathrm{pH}$ at $298 \mathrm{~K}\left(25^{\circ} \mathrm{C}\right)$ & A & A & A & 5.0 to 8.0 \\
\hline $\begin{array}{c}\text { Total organic carbon } \\
\text { (TOC), max, } \mu \mathrm{g} / \mathrm{L}\end{array}$ & 50 & 50 & 200 & no limit \\
\hline Sodium, max, $\mu \mathrm{g} /$ & 1 & 5 & 10 & 50 \\
\hline Chlorides, max, $\mu \mathrm{g} / \mathrm{L}$ & 1 & 5 & 10 & 50 \\
\hline Total silica, $\max , \mu g / L$ & 3 & 3 & 500 & no limit \\
\hline \multicolumn{5}{|c|}{$\begin{array}{l}\text { Microbiological contamination-When bacterial levels need to be controlled, } \\
\text { reagent grade types should be further classified as follows: }\end{array}$} \\
\hline & & Type A & Type B & Type C \\
\hline $\begin{array}{l}\text { Maximum heterotrophic } \\
\text { bacteria count }\end{array}$ & & $10 / 1000 \mathrm{~mL}$ & $10 / 100 \mathrm{~mL}$ & $100 / 10 \mathrm{~mL}$ \\
\hline Endotoxin, $\mathrm{EU} / \mathrm{ml}^{8}$ & & $<0.03$ & 0.25 & $\begin{array}{l}\text { not appli- } \\
\text { cable }\end{array}$ \\
\hline \multicolumn{5}{|c|}{$\begin{array}{l}\text { A The measurement of } \mathrm{pH} \text { in Type } \mathrm{I}, \mathrm{II} \text {, and III reagent waters has been } \\
\text { eliminated from this specification because these grades of water do not contain } \\
\text { constituents in sufficient quantity to significantly alter the } \mathrm{pH} \text {. } \\
{ }^{B} \mathrm{EU}=\text { Endotoxin Units. }\end{array}$} \\
\hline
\end{tabular}

Figure 6: ASTM D 1193 - 99 Water Types

The ATR reactor core water specification was set at a nominal pH of 5.0 in the 1960's on the basis of rapid heating tests that effectively showed that the minimum fuel corrosion rates occurred at a $\mathrm{pH}$ of $5.07^{\mathrm{xv}}$. However, the test data was obtained by using the aluminum sample as the heating element in the test with an applied current flow of up to 10,000 amps. The current flow effectively stripped away the positive charge on the surface hydroxide, thus eliminating the effect of passivation for the data set. That data set indicated that fuel corrosion continued indefinitely at a constant rate. In actual practice, however, the rate is about half of that predicted and then essentially stops because of passivation when the hydroxide layer reaches a limiting thickness.

As a best practice for research reactor fuel, maintenance of core water at the center of the passivation region (a pH of $5.4-6.0$ ) is recommended as it provides the most margin for abnormal water conditions without any significant effect on the fuel. Although this is higher than the tightly controlled ATR water system operating at 5.0, it is considered appropriate for the lower temperature and flux levels for research reactor fuel.

\subsection{Fuel Treatment}

New research reactor fuel elements of current designs with no pre-treatment, will grow a hydroxide surface layer during the first few days in reactor service. Depending on radiation levels, water quality, and fuel surface cleanliness at the time, this hydroxide formation may be entirely normal and acceptable or result in significant corrosion issues.

To obtain the thinnest, most conductive, most protective surface on the fuel and eliminate any potential for startup incidents, fuel surfaces should be pre-treated to achieve a consistent, fully-aged fuel hydroxide surface while the fuel is being manufactured and potential water quality and surface contamination issues

\footnotetext{
${ }^{\mathrm{d}}$ This equilibrium $\mathrm{pH}$ was originally defined in the Pourbaix diagram for the aluminum - water system.
} 
can be tightly controlled. Treatment to achieve a minimum hydroxide layer thickness of $0.3-0.5 \mu \mathrm{m}$ should be entirely sufficient.

If reactor water $\mathrm{pH}$ can be adequately controlled within a range of $\sim 5.4-6.0$, the pre-treatment process should be designed to provide fully aged, crystalline boehmite.

\subsection{Reactor Operation}

\subsubsection{Impacts of Reactor Operating Temperature}

Research reactors operating at temperatures from $30-40^{\circ} \mathrm{C}$ are not a threat to the thermal stability of the aluminum cladding or the hydroxide surfaces. Although formation of the tri-hydroxide forms are thermodynamically favored at the lower temperatures, history has shown that further hydration of the crystalline boehmite has not occurred in spent fuel that has been stored at low temperatures for many years ${ }^{\text {xvi,e }}$.

During reactor operation radiolysis reactions may tend to interact with the surface hydroxide causing a reduction or increases in layer thickness. Any increase will most probably be a deposition of bayerite over the boehmite. This is not problematic at the thicknesses involved $(<0.5 \mu \mathrm{m})$ as boehmite has the higher density and better bond strength with the base metal. Bi-layered hydroxides are common in aluminum reactor fuel and are not known to cause any significant issues.

\subsubsection{Reactor Shutdown Configuration}

The issue of whether to drain the water from the reactor core on shutdown or leave the fuel covered is not easily answered from the technical viewpoint. The core is designed to operate with flowing water. If the water quality is very good, water removal may not make any significant difference to the fuel. Draining the core when the water quality is poor (especially high conductivity and low $\mathrm{pH}$ ) nearly guarantees that contaminants in the water will be able to concentrate on hydroxide fuel surfaces as the water evaporates. These contaminants may allow the initiation of crevice corrosion cells bringing unwanted corrosion issues. Leaving the water in the core but turning off the pumps is also unacceptable from the corrosion viewpoint as the stagnant water invites both crevice and galvanic corrosion to proceed in susceptible locations.

\section{Summary/Conclusions}

Reduction of the thickness of the water annulus between fuel plates should not result in new or higher risks of fuel failure from aluminum corrosion if appropriate fuel plate fabrication and reactor operational practices are employed.

The best practices are summarized as follows:

\subsection{Fuel}

- Use a qualified, corrosion resistant aluminum or aluminum alloy for fuel cladding (AA6061, AA1070)

\footnotetext{
${ }^{\mathrm{e}}$ The relative stability of hydroxide forms is theoretically due to the hydrogen to oxygen bond length. This length is less for boehmite than for bayerite or gibbsite; therefore, once formed, the boehmite should be more stable, even at low temperatures.
} 
- Pre-treat the fuel during manufacture to achieve a well-aged crystalline boehmite of about $0.5 \mu \mathrm{m}$ thick.

\subsection{Reactor}

\subsubsection{Water}

- Maintain ASTM D 1193, Type II water quality if possible,

- Never put new fuel in poor quality core water (especially if it has not been pre-treated),

- Maintain the core water at a $\mathrm{pH}$ of $5.7 \pm 0.3$,

- Keep carbonates, sulfates, and chlorides out of the system if possible.

\subsubsection{Reactor Shutdowns}

- Do not let core water stagnate,

- Do not drain the core when water or air quality is poor. 


\section{References}

i Wefers, K., and Misra C., Oxides and Hydroxides of Aluminum, AlCOA Laboratories Technical Paper No. 19, Revised, 1987.

ii Gazapo, J. L., and Gea, J., Anodizing of Aluminum, Training in Aluminum Application Technologies, Lecture 5203, 1994.

iii Byalobzheskii, A.V., Radiation Corrosion, Izdatel stvo Nauka, Moskva 1967, Translated 1970 as AEC-TR 7096, pg. 17.

iv Sindelar, et.al., Corrosion of Metals and Alloys in High Radiation Fields, Materials Characterization, Vol. 43, pp. 147-157, 1999.

v Griebenow, M.L. et.al., TRA Oxide Film Control and Surveillance, EG\&G Idaho RE\&C Report RE-A-77-059, October 1977.

vi Hofman, G. L. to J. L. Snelgrove, Corrosion of Iowa State University UTR-10 Fuel Plates, Preliminary Report, Argonne National Laboratory, June 10, 1993.

vii Shaber, E. L., Iowa State Research Reactor Fuel Cladding Surface Quality Evaluation, Idaho National Engineering and Environmental Laboratory, EDF-TRA-ATR-1437, 3/19/1999.

viii Shaber, E. L., Micro-Pitting of 6061-O Aluminum Fuel Plates During Hydroxide Coating, Idaho National Engineering and Environmental Laboratory, EDF-730, Rev 0, 2/18/1998.

ix Martin. B., RTC ATR UFSAR Nuclear Safety Basis, Idaho National Laboratory, SAR - 153, $4 / 7 / 05$.

x Vinnola, A, Specification for Advanced Test Reactor Mark VII Zone Loaded Fuel Elements, INF-9-ATR, Revision 16, Idaho National Laboratory, SPC - 415, 3/17/05.

xi Miglin, B. P., Production of Boehmite Film on Aluminum, Babcock \& Wilcox Alliance Research Center, RDD:95:43227-001-000:01, September 1994.

xii Byalobzheskii, A.V., The Effect of Neutron Irradiation on the Corrosion of Aluminum in Water, Institute of Physical Chemistry, Academy of Sciences, USSR, May 1963.

xiii IAEA, Corrosion of Research Reactor Aluminum Clad Spent Fuel in Water, International Atomic Energy Agency Technical Report Series, ISSN 0074-1914; No. 418, Chapter 3, Guidelines for Corrosion Protection of Research Reactor Aluminum Clad Spent Nuclear Fuel in Interim Wet Storage, pg. 56-60.

xiv Castet, S., et.al., Boehmite Solubility and Aqueous Aluminum Speciation in Hydrothermal Solutions $\left(90-350^{\circ} \mathrm{C}\right)$ : Experimental Study and Modeling, Laboratorire de Geochimie-CNRS, Universite Paul-Sabatier, 38 rue des Trente-Six Ponts, May 1993. 
xv Griess, J.C., et.al., Effect of Heat Flux on the Corrosion of Aluminum by Water, Part IV. Tests Relative to the Advanced Test Reactor and Correlation with Previous Results, Oak Ridge National Laboratory, ORNL-3541, February 1964.

xvi Digne, M., et.al., Structure and Stability of Aluminum Hydroxides: A Theoretical Study, Journal of Physics and Chemistry B 2002, 106, pg. 5155 - 5162. 